\title{
Problem of conjugate heat transfer between main gas pipeline and frozen ground
}

\author{
Edward Bondarev ${ }^{1, *}$, Igor Rozhin $^{1}$, and Kira Argunova ${ }^{1}$ \\ ${ }^{1}$ Institute of Oil and Gas Problems, Siberian Branch, Russian Academy of Sciences, 677980 Yakutsk, \\ Oktyabskaya, 1, Russia
}

\begin{abstract}
Mathematical model of non-isothermal gas flow within the framework of tube hydraulics including change of tube cross-section due to hydrate formation and the dependence of coefficient of heat transfer between gas and hydrate layer on varying flow area is proposed. The corresponding conjugate problem of heat exchange between imperfect gas in the pipeline and the environment is reduced to the solution of differential equations describing non-isothermal flow of gas in pipes and heat transfer equations in ground with the corresponding conjugation conditions. In the quasi-stationary mathematical model of hydrate formation (dissociation), the dependence of gas-hydrate transition temperature on gas pressure is taken into account. Some decisions taken in the design of the first section of the main gas pipeline «Power of Siberia» have been analyzed. It has been shown that if gas is not sufficiently dried, outlet pressure may drop below the technological limit in about 6-7 hours. At the same time, for completely dry gas ,it is possible to reduce the cost of thermal insulation of the pipeline at least two fold.
\end{abstract}

The Power of Siberia main gas pipeline has been chosen for numerical experiment. It should transport natural gas from the Chayandinskoye and Kovyktinskoye fields located in the Sakha Republic (Yakutia) and the Irkutsk district [1]. At the first stage, the construction of the Chayanda - Lensk section is planned: length $207 \mathrm{~km}$, tube diameter $1.4 \mathrm{~m}$ and operating pressure $9.82 \mathrm{MPa}$. The section lays in almost continuous permafrost ground. In order to prevent undesirable consequences of the soil thawing, thermal insulation of a pipe made of Extrol-45 material (extruded polystyrene foam) $0.2 \mathrm{~m}$ thick and with a heat conductivity coefficient of $0.029 \mathrm{~W} /(\mathrm{m} \cdot \mathrm{K})$ is provided. Given the high cost of the material (approximately 6900 rubles per cubic meter), it is advisable to estimate alternative solutions. Additionally, the consequences of possible deviation from the design solution, which provides for a thorough gas drying before being supplied to the mainline are estimated in the paper. It is necessary because the reservoir conditions of the Chayandinskoye field (temperature $-282.15 \mathrm{~K}$, pressure - $13 \mathrm{MPa}$ ) [2] fully correspond to the equilibrium conditions of hydrate formation of natural gas. According to the project, its drying should bring the mole fraction of water to $0.0026 \%$.

\footnotetext{
*Corresponding author: bondarev@ipng.ysn.ru
} 
The analysis was performed within the framework of the mathematical model of hydrate formation during gas flow in pipes, proposed in the monograph [3] and modified in subsequent publications of the authors [4-9]. In the model gas flow in pipe with a crosssection that changes with time is described in a quasi-stationary approximation, since the rate of transition process in pipeline is much higher than that of temperature changes in surrounding frozen ground due to thermal conductivity. This means that time enters the equations parametrically through a variable ambient temperature and through changes of flow area. The propagation of heat in permafrost soils is described in the framework of the Stefan problem. These equations are complemented by the conditions of conjugation of heat flows. The quasi-stationary mathematical model of formation (dissociation) of hydrates in gas pipeline takes into account that the heat transfer coefficient from gas to inner wall of pipe depends on changing with time cross-section as well as that gas-hydrate phase transition temperature depends on flowing gas pressure.

In [3-9] it has been shown that the model can be reduced to a system of two ordinary nonlinear differential equations with respect to pressure and temperature:

$$
\begin{gathered}
\frac{d p}{d x}=-\frac{\sqrt{\pi} \psi M^{2}}{4 \rho_{\mathrm{g}} S^{2.5} S_{0}^{2.5}}, \\
\frac{d T}{d x}-\varepsilon \frac{d p}{d x}=\frac{\pi d \alpha}{c_{p} M}\left(T_{\mathrm{e}}-T\right),
\end{gathered}
$$

where $c_{p}$ - specific heat capacity of gas at constant pressure, $d$-diameter of cross-section, $M$ - constant mass flow rate, $p$ - pressure, $S$ - dimensionless cross-section, $S_{0}-$ dimensional cross-section before formation of hydrates, $T$ - temperature, $T_{\mathrm{e}}-$ temperature of surrounding frozen ground, $x$ - coordinate along pipe axis, $\alpha$ - total heat transfer coefficient between gas and surrounding ground, $\rho_{g}$ - gas density, $\psi$-hydraulic resistance coefficient, $\varepsilon=\frac{R T^{2}}{c_{p} p}\left(\frac{\partial \mathrm{Z}}{\partial T}\right)_{p}-$ throttle coefficient, $R-$ gas constant, $\mathrm{Z}=\mathrm{Z}(p, T)-$ gas imperfection coefficient, depending on ratio of pressure and temperature to their critical values $p_{\mathrm{c}}$ and $T_{\mathrm{c}}$. Here it is determined by the Berthelot equation in the form proposed in [10]:

$$
\mathrm{Z}=1+0.07 \frac{p}{p_{\mathrm{c}}} \frac{T_{\mathrm{c}}}{T}\left(1-6 \frac{T_{\mathrm{c}}^{2}}{T^{2}}\right)
$$

The equation describing the change of pipeline cross-section in time is written in dimensionless form:

$$
\frac{d S}{d \tau}=b_{2} \frac{T_{\mathrm{e}}-T_{\mathrm{h}}(p)}{1-b_{2} \ln S}-b_{1} \sqrt{S}\left(T_{\mathrm{h}}(p)-T\right)
$$

where $b_{1}=\alpha_{1} d_{0} / 4 \lambda_{\mathrm{h}}, b_{2}=\alpha_{2} d_{0} / 4 \lambda_{\mathrm{h}}, \alpha_{1}$ - coefficient of heat transfer between gas and hydrate layer; $\alpha_{2}$ - coefficient of heat transfer between hydrate layer and frozen ground, $d_{0}$ - pipe diameter before hydrate formation; $\tau=\frac{\lambda_{\mathrm{h}} T_{\mathrm{c}}}{\rho_{\mathrm{h}} q_{\mathrm{h}} d_{0}^{2}} t$-dimensionless time; $\lambda_{\mathrm{h}}, \rho_{\mathrm{h}}$ - coefficient of thermal conductivity and density of hydrate, $q_{\mathrm{h}}$ - latent heat of hydrate formation, $t-$ time, $T_{\mathrm{h}}(p)=a \ln p+b$ - equilibrium temperature of hydrate formation. The 
empirical coefficients $a$ and $b$ are found by approximating the thermodynamic equilibrium curve of hydrate formation according to the Sloan method [11]. In equation (3), all temperature values are related to the critical gas temperature $T_{\mathrm{c}}$, and the coefficient $\alpha_{1}$ depends on the area of the cross-section of the pipe $S$ that varies in time:

$$
\frac{\alpha_{1} d_{0}}{\lambda_{\mathrm{g}}}=0.023 \operatorname{Pr}^{0.43}\left(\frac{4 M}{\pi d_{0} \eta_{\mathrm{g}}}\right)^{0.8} \frac{1}{S^{0.9}},
$$

where $\lambda_{\mathrm{g}}, \eta_{\mathrm{g}}$ - thermal conductivity and dynamic viscosity of gas, $\operatorname{Pr}-$ the Prandtl number.

The ground temperature $T_{\mathrm{e}}$ is the solution of heat conduction equation, which is written in a form convenient for numerical solution using the enthalpy method. The corresponding initial-boundary value problem is solved under the assumption that the heat flux in each section of pipeline propagates strictly radially. The connection between sections is carried out through the solution of the equation describing the change of gas temperature in pipe and the boundary condition on its outer wall.

The calculations were performed with the following initial data: $c_{p}=2300 \mathrm{~J} /(\mathrm{kg} \cdot \mathrm{K})$, $d_{0}=1.4 \mathrm{~m}$, pipeline length $L=200 \mathrm{~km}, q_{\mathrm{h}}=510 \mathrm{~kJ} / \mathrm{kg}$, operating pressure $p_{0}=9.8 \mathrm{MPa}$, inlet temperature $T_{0}=282.15 \mathrm{~K}$, heat exchange coefficient with thermal insulation $\alpha_{0}=0.145 \mathrm{~W} /\left(\mathrm{m}^{2} \cdot \mathrm{K}\right), \quad \psi=0.02, \quad \lambda_{\mathrm{g}}=0.0307 \mathrm{~W} /(\mathrm{m} \cdot \mathrm{K}), \quad \lambda_{\mathrm{h}}=1.88 \mathrm{~W} /(\mathrm{m} \cdot \mathrm{K})$, $\eta_{\mathrm{g}}=1.3 \cdot 10^{-5} \mathrm{~Pa} \cdot \mathrm{s}, \rho_{\mathrm{h}}=920 \mathrm{~kg} / \mathrm{m}^{3}$, initial ground temperature $T_{\mathrm{fr}}=271.15 \mathrm{~K}$, temperature of ground thawing-freezing $T_{\mathrm{ph}}=273.15 \mathrm{~K}$, latent heat of ice-water phase transition $q_{\mathrm{ph}}=334.4 \mathrm{~kJ} / \mathrm{kg}$; for lightly icy sandy clays thermal conductivity and volume heat capacities in thawed and frozen states: $\lambda_{\mathrm{liq}}=1.6 \mathrm{~W} /(\mathrm{m} \cdot \mathrm{K}), \quad \lambda_{\mathrm{s}}=1.7 \mathrm{~W} /(\mathrm{m} \cdot \mathrm{K})$, $C_{\text {liq }}=2.8 \cdot 10^{6} \mathrm{~J} /\left(\mathrm{m}^{3} \cdot \mathrm{K}\right), \quad C_{\mathrm{s}}=2.1 \cdot 10^{6} \mathrm{~J} /\left(\mathrm{m}^{3} \cdot \mathrm{K}\right)$, respectively; density $\rho=1760 \mathrm{~kg} / \mathrm{m}^{3}$, moisture content $\omega=0.233$. The gas constant $R=453.524 \mathrm{~J} /(\mathrm{kg} \cdot \mathrm{K})$, critical parameters $p_{\mathrm{c}}=4.5 \mathrm{MPa}$ and $T_{\mathrm{c}}=195.075 \mathrm{~K}$, coefficients $a=10.73 \mathrm{~K}$ and $b=117.979 \mathrm{~K}$ were found for natural gas from the Chayandinskoye field for gas composition indicated above. Mass flow rate of gas is $M=700 \mathrm{~kg} / \mathrm{s}$. The pipes made of K60 steel with wall thickness $0.032 \mathrm{~m}$ and heat conductivity $68 \mathrm{~W} /(\mathrm{m} \cdot \mathrm{K})$ have burial depth $1.5 \mathrm{~m}$ above the top of pipe.

Two scenarios were considered: 1) perfect project development, that is, perfectly dried gas was supplied to the pipeline, which completely eliminated the formation of hydrates; 2) wet gas was supplied to the pipeline and, along with other parameters (gas pressure and temperature, ground thawing dynamics), hydrate formation dynamics was considered and calculations were carried out until the outlet pressure did not fall below $4 \mathrm{MPa}$. In each of the cases three variants of calculations were analyzed: 1) pipe insulation over the entire section; 2) insulation of the initial part of pipe, the length of which was determined by the condition that the temperature at the contact of outer surface of pipe with the ground $T_{\mathrm{w}}$ is equal to thawing-freezing temperature of soils $T_{\mathrm{ph}} ; 3$ ) lack of insulation.

Analysis of the results begins with the first scenario (Fig. 1 - Fig. 4). The main conclusion that follows from the curves presented in these figures: substantial cooling of gas due to its throttling significantly reduces the risk of thawing frozen ground. Moreover, for a fully insulated pipeline gas is cooled below the freezing point of water in the ground in about $100 \mathrm{~km}$, while temperature at the contact of pipeline with the ground is always below it (Fig. 1a), that is, the ground should not be thawed. 

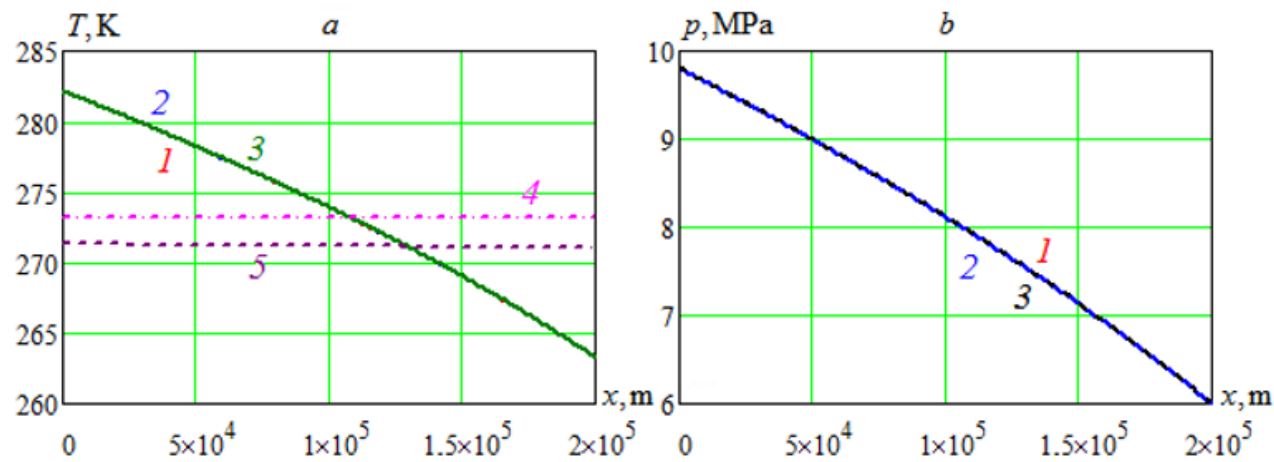

Fig. 1. Distribution of gas temperature $(a)$ and pressure $(b)$ along the fully insulated gas pipeline: $1-t=4.2 \mathrm{~min} ; 2-t=70$ hours; $3-t=120$ hours; $4-T_{\mathrm{ph}} ; 5-T_{\mathrm{w}}$ at $t=120$ hours

For pipeline with partial thermal insulation (first $90 \mathrm{~km}$ ) the contact temperature $T_{\mathrm{w}}$ after 5 days becomes equal to the phase transition temperature $T_{\text {ph }}$ only at the initial interval (approximately $30 \mathrm{~km}$ ), and then decreases significantly (Fig. 2). It indicates that the cost of insulation can be reduced at least twice.

As it is expected, without thermal insulation gas temperature at the initial interval is slightly lower than with partial one, and then they both become equal (see curves 1 and 3 in Fig. 3). The contact temperature $T_{\mathrm{w}}$ in the absence of thermal insulation exceeds the phase transition temperature $T_{\mathrm{ph}}$ in the initial part of approximately $25 \mathrm{~km}$ (curve 5 in Fig. 3). In this case ground thaws approximately at the same distance, and the thawing radius after 5 days does not exceed $0.8 \mathrm{~m}$.

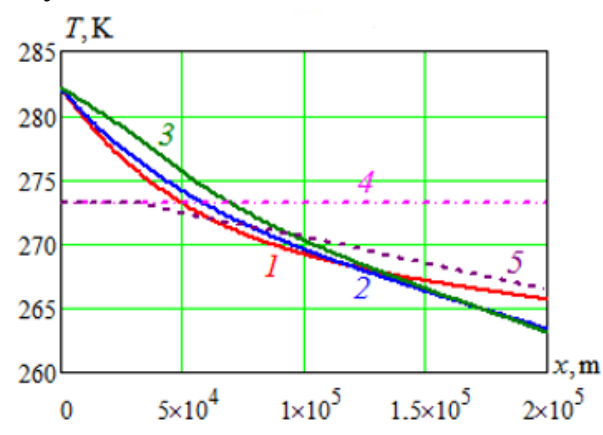

Fig. 2. Distribution of gas temperature along partially insulated gas pipeline: $1-t=4.2$ $\min ; 2-t=70$ h.; $3-t=120$ h.; $4-T_{\mathrm{ph}} ; 5-$ $T_{\mathrm{w}}$ at $t=120 \mathrm{~h}$.

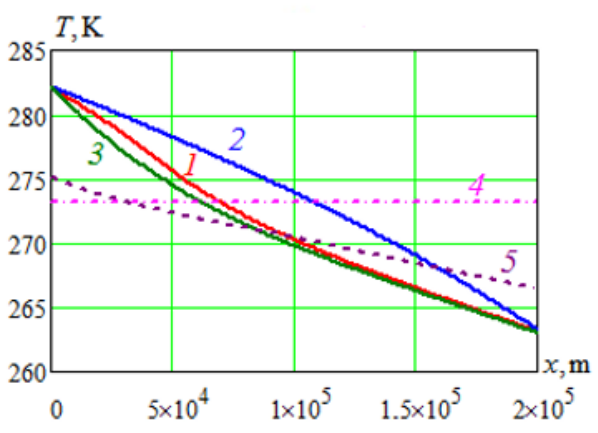

Fig. 3. Distribution of gas temperature along pipeline after $120 \mathrm{~h}$. for various types of thermal insulation: 1 - partial; 2 - full length; 3 -no insulation; $4-T_{\mathrm{ph}} ; 5-T_{\mathrm{w}}$

Let us proceed to the analysis of the results of calculations for the second scenario when the possibility of gas hydrates formation should be considered. The results are presented at Fig. 4 - Fig. 6. Naturally, in this case reduction pipe cross-section due to growth of hydrate layer was taken into account and the calculations continued until the outlet pressure became $4 \mathrm{MPa}$.

First of all we note that computation time during simulation of the second scenario is significantly reduced, which means that the formation of hydrates is quite intensive, and in about 7 hours the outlet pressure decreases to the specified value. At the same time gas temperature is everywhere below the equilibrium temperature of hydrate formation and this difference increases with time (compare curves 1 and 2 in Fig. 4 and Fig. 5). More important that in this case temperature at the contact of pipe with ground $T_{\mathrm{w}}$ is always lower 
than its thawing temperature $T_{\mathrm{ph}}$ (compare curves 4 and 5 in Fig. 4 and Fig. 5). Here the effect of so-called "thermal curtain" is manifested, the role of which is performed by forming hydrate layer. Because of this effect the temperature distribution along partially insulated pipeline and without insulation one is almost the same. Therefore, only the results for the last variant of calculations are presented here (Fig. 5).

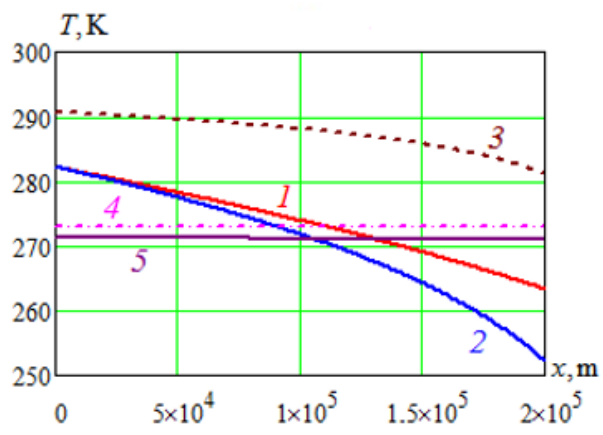

Fig. 4. Distribution of gas temperature along the fully insulated gas pipeline: $1-t=4.2$ $\min ; 2-t=7 \mathrm{~h} . ; 3-T_{\mathrm{h}}$ at $t=7 \mathrm{~h} . ; 4-T_{\mathrm{ph}} ; 5-$ $T_{\mathrm{w}}$ at $t=7 \mathrm{~h}$.

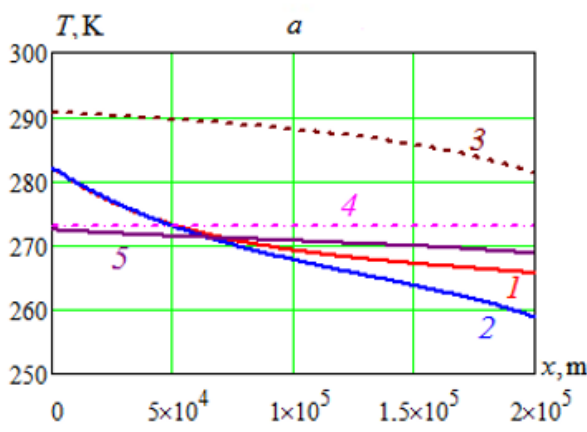

Fig. 5. Distribution of gas temperature along pipeline without heat insulation: $1-t=4.2$ $\min ; 2-t=6.3 \mathrm{~h} . ; 3-T_{\mathrm{h}}$ at $t=6.3 \mathrm{~h} . ; 4-T_{\mathrm{ph}}$; $5-T_{\mathrm{w}}$ at $t=6.3 \mathrm{~h}$.

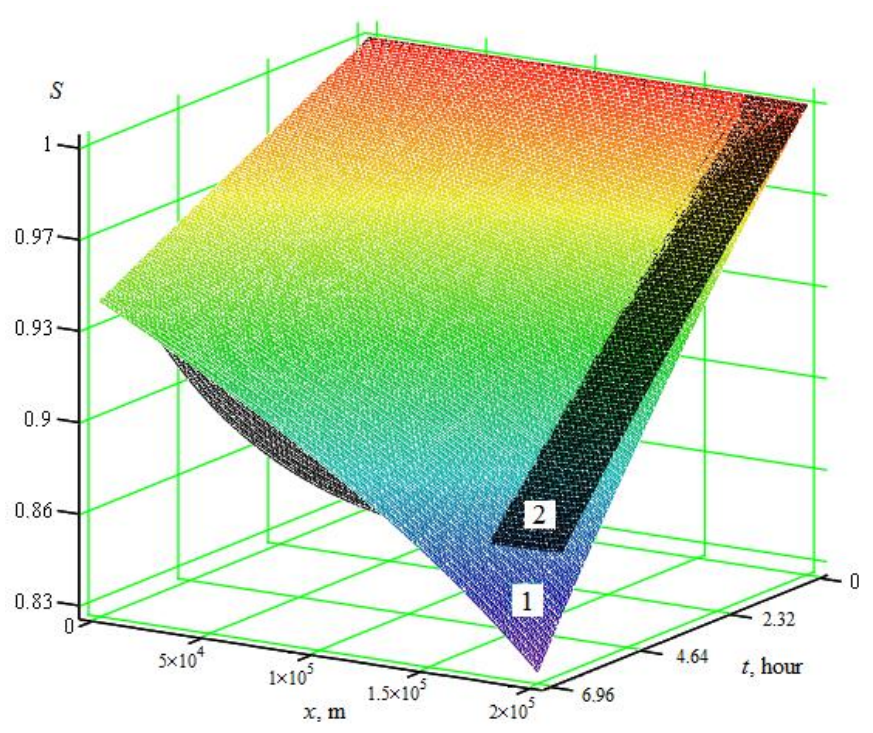

Fig. 6. The dynamics of distribution of dimensionless cross-section: 1 - full thermal insulation; 2 lack of thermal insulation.

The dynamics of cross-section distribution along the pipe is illustrated at Fig. 6. It shows that the effect of thermal insulation on the thickness of hydrated layer is ambiguous. In the presence of thermal insulation thickness of hydrated layer is less than in absence of the insulation almost along the entire length (approximately $170 \mathrm{~km}$ ) of gas pipeline. However, in the final section the situation is reversed (compare surfaces 1 and 2 at Fig. 6).

The presented results allow to draw the following practically important conclusion: the problems of thermal interaction of gas flow in pipelines with surrounding grounds are generally conjugated. A simplified mathematical model in which ground temperature is assumed to be constant leads to a significant underestimation of time of hydrate plug formation. 
To ensure accident-free and cost-effective operation of a main gas pipeline, forecasting and systematic control over its thermal regime are necessary. The reliability of such systems is especially important for main gas pipelines operating in climatic, geocryological and hydrological conditions as is the case for the planned Power of Siberia gas pipeline.

The results of the computational experiment provide means of: 1) estimating the risk of emergency pressure drop after insufficient gas drying; 2) reducing cost of thermal insulation of pipeline. It is shown that in case of insufficient dehydration outlet pressure of gas can decrease below the permissible limit in about 6 to 7 hours. At the same time for completely dry gas it is possible to reduce the cost of thermal insulation of gas pipeline by at least twice.

\section{References}

1. http://fb.ru/article/198838/magistralnyiy-gazoprovod-sila-sibiri-shema.

2. V. F. Perepelichenko, Elektronnyi nauchnyi zhurnal «Georesursy. Geoenergetika. Geopolitika», Prospects for developing a unique oil and gas condensate field of Yakutia 1(5), 8 (2012) http://oilgasjournal.ru/vol_5/perepelich.pdf [in Russian]

3. E. A. Bondarev, V. I. Vasil'ev, A. F. Voevodin, N. N. Pavlov, A. P. Shadrina, Thermohydrodynamics of gas production and transportation systems, 272 (Novosibirsk: Nauka. Sibirskoe otdelenie, 1988) [in Russian]

4. E. A. Bondarev, I. I. Rozhin, K. K. Argunova, Journal of Mining Institute, Features of mathematical modeling of natural gas production and transport systems in the Russia's arctic zone, 228, 705-716 (2017)

5. K. K. Argunova, E. A. Bondarev, I. I. Rozhin, Earth's Cryosphere, Mathematical models of hydrate formation in gas wells, 15, 2, 65-69 (2011)

6. E. A. Bondarev, K. K. Argunova, Mathematical models of hydrate formation in gas wells // Information and Mathematical Technologies in Science and Management: Proceedings of 14th Baikal All-Russian Conference. Part 3, 41-51 (Irkutsk: ISEM SO RAN, 2009) [in Russian]

7. E. A. Bondarev, I. I. Rozhin, K. K. Argunova, Journal of Engineering Physics and Thermophysics, Modeling the formation of hydrates in gas wells in their thermal interaction with rocks, 87, 4, 900-907 (2014) DOI: 10.1007/s10891-014-1087-0.

8. E. A. Bondarev, I. I. Rozhin, A. F. Voevodin, K. K. Argunova, Thermohydrodynamics of main gas pipeline "Power of Siberia» / Problems of complex systems' optimization: Proceedings of 12th International Asian School-seminar. December 12-16, Akademgorodok, Novosibirsk, Russia, 79-86 (2016) [in Russian]

9. E. A. Bondarev, A. F. Voevodin, Solution of pipe hydraulics problems: Natural gas production and transportation systems, 209 (Novosibirsk: Izdatel'stvo SO RAN, 2017) [in Russian]

10. I. I. Vukalovich, I. I. Novikov, Equations of real gas state, 343 (Moscow-Leningrad: Gosenergoizdat, 1948) [in Russian]

11. E. D. Sloan, C. A. Koh, Clathrate hydrates of natural gases, 720 (Boca Raton: Taylor\&Francis Group/CRC Press, 2008) 